\title{
Molecular and cytogenetic analysis of a familial microdeletion of $\mathrm{Xq}$
}

\author{
Stephen Wells, Sarah Mould, D Robins, David Robinson, Patricia Jacobs
}

\begin{abstract}
Cytogenetic analysis of a male infant referred for poor neurological development and failure to thrive showed a microdeletion of the $X$ chromosome, his karyotype being 46,Y,del(X)(pter $\rightarrow$ q21.1:: q21.2 $\rightarrow$ qter). His mother and grandmother were also found to carry the deletion. DNA probes were used to define the deletion molecularly and it was shown to span intervals 2 to 6 of Cremers et al, a portion of $X_{q}$ that contains the TCD gene and genes whose absence is associated with deafness and mental retardation. RFLP analysis together with $\mathrm{X}$ inactivation studies using the probe $M 27 \beta$ verified the carrier status of the female relatives and showed non-random $X$ inactivation in the heterozygous females.
\end{abstract}

Cytogenetically detectable deletions of the $\mathrm{X}$ chromosome compatible with viability in the male are very rare and those reported to date have involved either band Xp21 or Xq21. The great majority of Xq21 deletions have been ascertained through males with choroideremia associated with other developmental problems. Recently, attempts have been made to define such Xq21 deletions molecularly and to use overlapping deletions to map contiguous genes. Using this approach, Cremers et al ${ }^{1}$ characterised six deletions involving band $\mathrm{Xq} 21$ in an attempt to map the genes for choroideremia and the genes for deafness and mental retardation, which are often found in patients with complex syndromes and Xq21 deletions. Using a series of 20 probes previously mapped to Xq21, they divided the band into seven intervals and provided evidence that choroideremia

Wessex Regional Genetics Laboratory, General Hospital, Fisherton Street, Salisbury SP2 7SX.

S Wells, S Mould, D Robinson, P Jacobs

South West Surrey Health Authority, St Luke's Hospital, Warren Road, Guildford, Surrey GU1 3NT.

D Robins

Correspondence to $\mathrm{Mr}$ Wells.

Received for publication 3 July 1990

Revised version accepted for publication 17 September 1990. was associated with absence of interval 3, while deafness and mental retardation were associated with deletions of interval 2. Recently, Merry $e t a l^{2}$ studied a female with choroideremia and a de novo X;13 translocation. The $X$ translocation breakpoint in Xq21.2 was mapped by pulse field gel electrophoresis to within $120 \mathrm{~kb}$ of locus DXS165. This suggests that the choroideremia gene lies between loci DXS165 and DXS95 in interval 3 of Cremers et al, ${ }^{1}$ assuming that the translocation breakpoint is within the gene.

We have recently studied a family in which the proband, a male infant, referred to us for cytogenetic investigation because of a suspected neurological problem, had a deletion of band Xq21. Studies of other family members showed his mother and his maternal grandmother to have a similar deletion. This paper reports the results of the cytogenetic and molecular investigations of this family.

\section{Case report}

The proband was a male infant born by vertex delivery after spontaneous onset of labour at 39 weeks' gestation. The mother was a 21 year old primigravida and the father 26 years old. At birth the infant weighed $2150 \mathrm{~g}$ ( $<3 \mathrm{rd}$ centile), his head circumference was $32 \mathrm{~cm}$ ( 3 rd centile), but no obvious dysmorphic features were noted. He was polycythaemic (haemoglobin $23.7 \mathrm{~g} / \mathrm{dl}$, PCV 0.71) and a partial exchange using $40 \mathrm{ml}$ of plasma was undertaken.

The child was admitted to hospital at 3 months of age with diarrhoea and vomiting and it was noted that he was somewhat floppy and not as socially responsive or visually alert as expected. An EEG showed minor intermittent abnormalities in the right posterior quadrant but was otherwise normal. Visual evoked response showed no evidence of any serious impairment of visual pathways or of the occipital cortex, and the electroretinogram was normal. Cranial ultrasound showed no abnormality and his serum immunoglobulins were normal for his age. A chromosome analysis was requested at this time and found to be abnormal with a microdeletion in the long arm of the $\mathrm{X}$, the karyotype being 46,Y, $\operatorname{del}(\mathrm{X})(\mathrm{q} 21.1 \mathrm{q} 21.2)$. Because the deletion was similar to those previously reported to be associated with choroideremia, 
deafness, and mental retardation, attention was focused on vision and hearing. The ophthalmological opinion at 3 months was that "there were wide oscillatory movements of the fundus, the macula was not well developed and the periphery was not seen well". The child is thought to have sensorineural hearing loss in addition to secretory otitis media and hearing aids have been provided.

From the age of 10 months there have been seizurelike episodes when the head is thrown back and the eyes turn up and oscillate rapidly up and down. The patient was treated with carbamazepine and the episodes have not occurred recently. He shows marked delay in his developmental progress and currently, at the age of 18 months, has incomplete head control and is not able to sit unsupported.

\section{CYTOGENETIC STUDIES}

Chromosome analysis of the peripheral blood of the proband after GTL banding showed an interstitial deletion of the $\mathrm{X}$ chromosome in all cells examined. The breakpoints were identified as q21.1 and q21.2, the resulting karyotype being $46, \mathrm{Y}, \operatorname{del}(\mathrm{X})(\mathrm{pter} \rightarrow$ q21.1::q21.2 $\rightarrow$ qter) (fig 1A). Cytogenetic studies were undertaken on other family members (fig 2). An identical interstitial deletion of the long arm of the $\mathrm{X}$ chromosome was found in the proband's mother (III.2) and grandmother (II.1) (fig 1B and C). The proband's father (III.1) and a maternal cousin (III.3)
1

II

IV

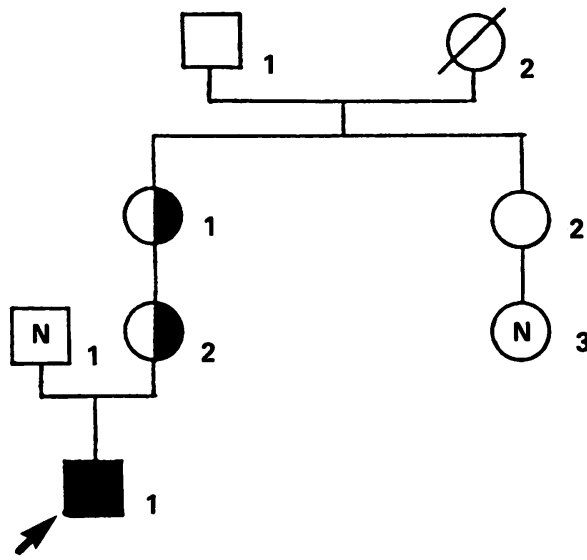

Figure 2 Pedigree of family.

were both found to have a normal chromosome constitution.

Cultures of the two females heterozygous for the deletion were treated with $30 \mu \mathrm{g} / \mathrm{ml}$ of BrdU six hours before harvest in an attempt to determine the replication status of the deleted X chromosome. Unfortunately, because of the small size of the deletion, it was difficult to distinguish between the normal $X$ and the deleted $\mathrm{X}$ with certainty in cultures treated with BrdU. Thus, the status of replication of the abnormal $\mathrm{X}$ chromosome was equivocal using this technique.
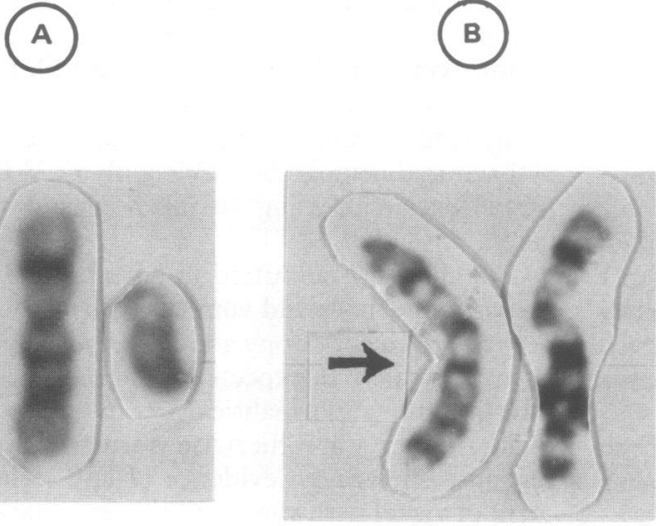

III.2
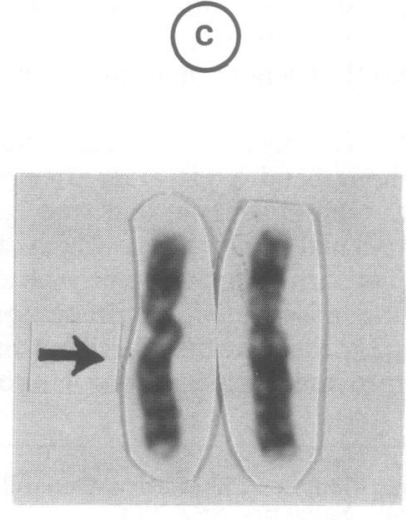

II.1

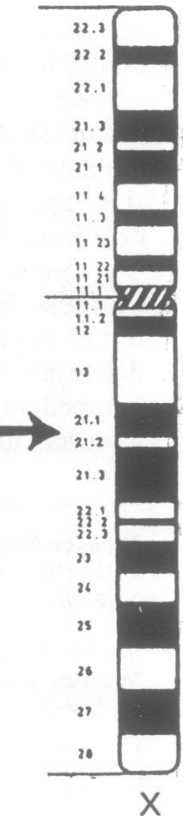

Figure 1 Sex chromosomes of $(A)$ the proband, $(B)$ his mother, and $(C)$ his grandmother showing the deletion in band q21.1. 
Analysis using six Xq21 probes.

\begin{tabular}{|c|c|c|c|c|c|c|c|c|}
\hline \multirow[b]{2}{*}{ Locus } & \multirow[b]{2}{*}{ Probe } & \multirow[b]{2}{*}{ Interval } & \multicolumn{6}{|c|}{ Family members } \\
\hline & & & I.1 & II.1 & III.1 & III. 2 & III. 3 & IV.1 \\
\hline $\begin{array}{l}\text { DXS72 } \\
\text { DXS121 } \\
D X S 95 \\
D X Y S 1 \\
D X S 3\end{array}$ & $\begin{array}{l}\text { pX65H77 } \\
\text { p784 } \\
\text { pXG7c } \\
\text { pDp34 } \\
\text { p19.2 }\end{array}$ & $\begin{array}{l}1 \\
2 \\
3 \\
4 \\
6\end{array}$ & $\begin{array}{l}\overline{P r e s e n t} \\
\text { Present } \\
11 \mathrm{~kb} \\
2 \cdot 9 / 2 \cdot 1 \mathrm{~kb}\end{array}$ & $\begin{array}{l}\text { Present } \\
\text { Present } \\
\text { Present } \\
11 \mathrm{~kb} \\
2 \cdot 9 / 2 \cdot 1 \mathrm{~kb}\end{array}$ & $\begin{array}{l}\text { Present } \\
\text { Present } \\
\text { Present } \\
11 \mathrm{~kb} \\
5.1 \mathrm{~kb}\end{array}$ & $\begin{array}{l}\text { Present } \\
\text { Present } \\
\text { Present } \\
12 \mathrm{~kb} \\
2 \cdot 9 / 2 \cdot 1 \mathrm{~kb}\end{array}$ & $\begin{array}{l}- \\
\bar{z} \\
\overline{11} \mathrm{~kb} \\
2 \cdot 9 / 2 \cdot 1 \mathrm{~kb} \\
+ \\
5 \cdot 1 \mathrm{~kb}\end{array}$ & $\begin{array}{l}\text { Present } \\
\text { del } \\
\text { del } \\
\text { del } \\
\text { del }\end{array}$ \\
\hline DXS118 & p776 & 7 & Present & Present & - & Present & - & Present \\
\hline
\end{tabular}

\section{DNA ANALYSIS}

DNA was isolated from whole blood, cut with appropriate restriction enzymes, and Southern blotted by methods standard in our laboratory. ${ }^{34}$ In order to define the deletion, we studied the segregation of six probes spanning Xq21 and the results are shown in the table. As can be seen, locus $D X S 72$ in interval 1 and locus $D X S 118$ in interval 7 were present in the proband (IV.1), while loci DXS121, $D X S 95, D X Y S 1$, and $D X S 3$, located in intervals $2,3,4$, and 6 respectively, were absent. Thus the deletion in our patient spans intervals 2 to 6 of Cremers et al. ${ }^{1}$

Furthermore, a TaqI digest showed the proband's grandmother (II.1) to have an $11 \mathrm{~kb}$ allele at locus DXYS1, while his mother (III.2) had a $12 \mathrm{~kb}$ allele. As they do not have an allele in common at this locus, hemizygosity for III. 2 is established. Locus $D X S 3$ was absent in the proband but the maternal cousin (III.3) was found to be heterozygous, having both the $2 \cdot 9 / 2 \cdot 1 \mathrm{~kb}$ and the $5 \cdot 1 \mathrm{~kb}$ alleles, confirming the cytogenetic observation that she does not carry the deletion.

The $\mathrm{X}$ inactivation status of the two females heterozygous for the deletion was determined using Southern blotting and the probe $M 27 \beta$, a minisatellite probe defining locus $D X S 255$ on the proximal short arm of the $\mathrm{X}$ chromosome. M27 $\beta$ recognises a site that is methylated on active $\mathrm{X}$ chromosomes and non- methylated on inactive $\mathrm{X}$ chromosomes. ${ }^{56}$ It also shows heterozygosity in over $90 \%$ of females when cut with the restriction enzyme $M s p I .{ }^{7}$ We used $M s p I$ and its isoschizomer HpaII, which will not cut if the restriction site is methylated. Thus, females heterozygous for $M 27 \beta$ and in whom $X$ inactivation is random will have similar bands on both $M s p I$ and HpaII digests. However, if $\mathrm{X}$ inactivation is nonrandom the band in the $M s p I$ digest that represents the active $\mathrm{X}$ will be absent or of reduced intensity in the HpaII digest.

As can be seen from fig 3, the great grandfather (I.1) had a $10.2 \mathrm{~kb}$ allele for $M 27 \beta$ and both the grandmother and mother had a $10.2 \mathrm{~kb}$ and an $11 \cdot 2$ kb allele after digestion with $M s p I$. However, after digestion with $\mathrm{HpaII}$ the $10.2 \mathrm{~kb}$ allele, representing the active $\mathrm{X}$, was completely absent in II. 1 and present as only a very faint band in III.2. Thus, the two females heterozygous for the deletion clearly showed non-random $\mathrm{X}$ chromosome inactivation. Furthermore, the active $\mathrm{X}$ in II.1 was that inherited from her father. Therefore, if we assume the deleted $\mathrm{X}$ to be the one that is selectively inactivated, it must have been inherited from I.2, either as a de novo mutation or as a segregant chromosome, I.2 herself being a deletion carrier. III. 3 had two bands of approximately equal intensity after $H p a I I$ digestion, showing random $\mathrm{X}$ inactivation and thus confirming the cytogenetic and molecular analysis.

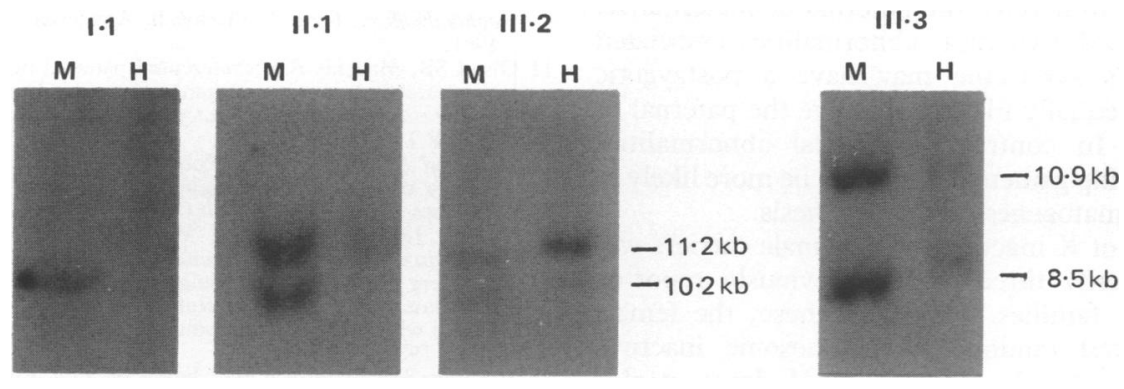

Figure 3 Southern blots of I.1, II.1, III.2, and III.3 digested with MspI(M) and HpaII(H) and probed with M27ß. The HpaII digests show the absence of the $10 \cdot 2$ allele in $I I .1$; the presence of the $10 \cdot 2 \mathrm{~kb}$ allele in very reduced amounts by comparison with the $11.2 \mathrm{~kb}$ allele in III.2; and the presence of 10.9 and $8.5 \mathrm{~kb}$ alleles in approximately equal amounts in III.3. 


\section{Discussion}

The six previously reported cases known to us of male patients with a cytogenetically detectable deletion of part of the long arm of the $\mathrm{X}$ chromosome have all involved band Xq21. ${ }^{1}$ Four of these were ascertained through a proband with choroideremia, and two through boys with multiple abnormalities. ${ }^{89}$ On reexamination at the age of 5 years, one of these boys had developed signs of choroideremia, ${ }^{8}$ but the other was ophthalmologically normal at the age of $10 .^{9}$ Our patient showed no signs of choroideremia at 18 months. However, the age of onset of choroideremia is variable and the earliest age at which it has been detected is $31 / 2$ years. ${ }^{10}$ As the gene for choroideremia has been localised between probes DXS165 and DXS95 in Xp21.2, ${ }^{2}$ the two patients who lack this segment of DNA but who do not yet have choroideremia will presumably develop it in the future.

The observation that all seven patients with male viable deletions of $\mathrm{Xq}$, including the three ascertained independently of choroideremia, had deletions involving band Xq21 suggests either that this region of the $\mathrm{X}$ is particularly susceptible to chromosome breakage or that deletions involving this region are male viable and thus relatively easy to ascertain. It is of interest that the only other $\mathrm{X}$ chromosome deletion in a male identified in our laboratory also involved band $\mathrm{Xq} 21$ and was seen in a routine prenatal amniotic specimen tested for maternal age. The pregnancy was terminated and family studies showed the mother to be heterozygous for the deletion and to be a de novo mutant, the chromosomes of her parents being normal.

In all six previously reported males with del(Xq21) and the two seen in our laboratory, the deletion was found to be familial, although five were ascertained through a single affected male. The absence of de novo mutants may reflect the fact that such deletions usually occur during male gametogenesis. It has been suggested that most autosomal structural abnormalities arise in the male. ${ }^{11}$ However, recent work on structural abnormalities of the $\mathrm{X}$ chromosome associated with Turner's syndrome $e^{12} 13$ suggests that these are equally likely to involve the paternal or maternal $\mathrm{X}$. The majority of structural abnormalities associated with Turner's syndrome may have a postzygotic origin that is equally likely to involve the paternal or maternal $X$. In contrast, structural abnormalities occurring during gametogenesis may be more likely to occur in spermatogenesis than oogenesis.

The status of $\mathbf{X}$ inactivation in female carriers was recorded in only three of the previously reported deleted Xq21 families. In two of these, the female carriers showed random $\mathrm{X}$ chromosome inactivation. ${ }^{8} 14$ In the family reported by Hodgson et al, ${ }^{15}$ the proband's sister had a late replicating deleted $\mathrm{X}$ in $100 \%$ of her lymphocytes while two carrier nieces had a small proportion of cells in which the normal $\mathrm{X}$ was late replicating.

We studied $\mathrm{X}$ inactivation by molecular rather than by cytogenetic techniques. Our proband's grandmother showed complete non-random $\mathrm{X}$ inactivation of her peripheral leucocytes, but the proband's mother showed a minor population of leucocytes in which the deleted $X$ was active. Our results are therefore similar to those of Hodgson et al, ${ }^{15}$ the older subjects showing complete non-random $\mathrm{X}$ inactivation in their leucocytes while the younger subjects had a minor population of cells in which the abnormal X was active. This suggests that selection against cells in which the abnormal $\mathrm{X}$ is active may be a rather slow process, at least in leucocytes, and may not be complete after 20 years.

We are grateful to Dr Helen Foley and Dr Frances Howard for their help with this family.

1 Cremers FPM, Van de Pol JR, Diergaarde PJ, et al. Physical fine mapping of the choroideremia locus using Xq21 deletions associated with complex syndromes. Genomics 1989;4:41-6.

2 Merry DE, Lesko JG, Siu V, et al. DXS165 detects a translocation breakpoint in a woman with choroideremia and a de novo $\mathrm{X} ; 13$ translocation. Genomics 1990;6:609-15.

3 Jacobs PA, Betts PR, Cockwell AE, et al. A cytogenetic and molecular reappraisal of a series of patients with Turner's syndrome. Ann Hum Genet 1990;54:209-23.

4 Robinson DO, Boyd Y, Cockburn D, Collinson MN, Craig I, Jacobs PA. The parental origin of de novo $\mathrm{X}$-autosome translocations in females with Duchenne muscular dystrophy revealed by M27\% methylation analysis. Genet Res Camb 1990;56:135-40.

5 Boyd Y, Fraser NJ. Methylation patterns at the hypervariable X chromosome locus DXS255 (M27ß); correlation with X inactivation status. Genomics 1990;7:182.

6 Brown RM, Fraser NJ, Brown GK. Differential methylation of the hypervariable locus DXS255 on active and inactive X chromosomes correlates with the expression of an X-linked disease. Genomics 1990;7:215.

7 Fraser NJ, Boyd Y, Craig I. Isolation and characterisation of a human variable copy number tandem repeat at Xcen-p11.22. Genomics 1989;5:146-8.

8 Tabor A, Andersen O, Lundsteen C, Niebuhr E, Sardemann H. Interstitial deletion in the 'critical region' of the long arm of the $\mathrm{X}$ chromosome in a mentally retarded boy and his normal mother. Hum Genet 1983;64:196-9.

9 Cremers FPM, van de Pol TJR, Wieringa B, et al. Molecular analysis of male-viable deletions and duplications allows ordering of 52 DNA probes on proximal Xq. Am f Hum Genet 1988;43:452-61.

10 Waardenburg PJ, Franceschetti A, Klein D. Genetics and ophthalmology. Oxford: Blackwell, Amsterdam: Van Gorcum, 1961.

11 Olson SB, Magenis RE. Preferential paternal origin of de novo structural chromosome rearrangements. In: Daniels $\mathrm{A}$, ed. The cytogenetics of mammalian autosome rearrangements. New York: Âlan R Liss, 1988:583.

12 Harbison M, Hassold T, Kobryn C, Jacobs PA. Molecular studies of the parental origin and nature of human $X$ isochromosomes. Cytogenet Cell Genet 1988;47:217-22.

13 Connor JM, Loughlin SA. Molecular genetics of Turner's syndrome. Acta Paediatr Scand Suppl 1989;356:77-81.

14 Rosenberg T, Niebuhr E, Yang HM, Parving A, Schwartz M. Choroideremia, congenital deafness and mental retardation in a family with an X chromosomal deletion. Ophthalmic Paediatr Genet 1987;8:139-43.

15 Hodgson SV, Robertson ME, Fear CN, et al. Prenatal diagnosis of X-linked choroideremia with mental retardation, associated with a cytologically detectable X-chromosome deletion. Hum Genet 1987;75:286-90. 